\title{
Internet of things (IoT) embedded smart sensors system for agriculture and farm management
}

\author{
Arshad Ali *, Sami Alshmrany \\ Faculty of Computer and Information Systems, Islamic University of Madinah, Almadinah Almunwarah, Saudi Arabia
}

\section{A RT ICLE INFO}

\section{Article history:}

Received 8 January 2020

Received in revised form

12 May 2020

Accepted 15 June 2020

\section{Keywords:}

Internet of things

Wireless sensor networks

Smart agriculture

Smart farm

Smart harvesting

\begin{abstract}
A B S T R A C T
Due to the enhancement of sensing technology in recent years, the researcher community embedding it to solve the real-life problems of physical and environmental types. Smart technology needs to be embedded in agriculture and farming to increase the crop to get more economic benefits. Agriculture and farming is core occupation since the human being start living on the earth, and with the passage of time, it is being modernized by using technologies for forming purposes. In the last half-century, due to modernization in technology along with electronics, the way of farming has been modernized and still in progress. Internet of Things (IoT) gives a new aspect in the field of smart farming and agriculture domain. With the use of a smart sensor system embedded with IoT, it revolutionized the way of farming and crop management and made it easy to monitor the agriculture farms. For improving the product and increasing the yield, temperature, moisture, humidity, and pest control are key components to be monitored and controlled. In this research work, an automatic Plant Irrigation System is proposed, which embedded smart sensor systems and IoT for the purpose of monitoring and managing the farm, which automatically provides water to plants and keeps updated by generating a message. In the proposed framework, several features are embedded, e.g., remote monitoring, intruder caring, temperature, and moisture sensing, security, leaf wetness, and irrigation facilities. To control these parameters via IoT, the system is connected with a remote device by interfacing a sensor system with a microcontroller. The proposed system is simulated, and the results are presented in the latter part of this paper, which is very much satisfied for further enhancement of this research work.
\end{abstract}

(C) 2020 The Authors. Published by IASE. This is an open access article under the CC BY-NC-ND license (http://creativecommons.org/licenses/by-nc-nd/4.0/).

\section{Introduction}

In the modern age, with the advancement in technologies and the Internet of Things (IoT), it is time to embed the wireless sensor network with IoT to facilitate the farmers to monitor and manage its crop to increase the yield to earn more revenue. In most countries watering plant method is used the old style of flooding in which almost 70 to $80 \%$ (FAO, 2017; Zhang and Shen, 2019) waste water resources. By using the proposed system will enable the farmer to irrigate the crop as required, and the proposed system is automated whenever and wherever water is needed to irrigate the crop. Ecological agricultural

\footnotetext{
* Corresponding Author.

Email Address: a.ali@iu.edu.sa (A. Ali) https://doi.org/10.21833/ijaas.2020.10.005

(1) Corresponding author's ORCID profile:

https://orcid.org/0000-0001-5625-0867

2313-626X/@ 2020 The Authors. Published by IASE.

This is an open access article under the CC BY-NC-ND license

(http://creativecommons.org/licenses/by-nc-nd/4.0/)
}

practices help to meet immediate societal needs while guarding the land and other natural resources for future generations (Suarez et al., 2016).

In recent times, climate change is inflicting unfavorable conditions on agriculture, causing setbacks in productivity (Yang et al., 2018). Interestingly, the research topic is very much important in the current scenario of the Kingdom of Saudi Arabia as there are not a lot rains and rivers. Also, there is no canal system in KSA to irrigate the crop, which makes easy for the farmer to grow their crops with high yield and it makes KSA reduce the import bill for the eatables. By adopting the proposed systems in agriculture, it will make it easy to feed humans as the population is increasing so rapidly, and the commodities are becoming expensive every day. The proposed system is most important in terms of humanity and socially.

Agriculture is a very old occupation as human life on the earth, and human starts cultivating the crops for its need to survive on the earth. With the passage of time, modernization is also embedded in 
agriculture for better crops and yields. Watering plant is the key area to be worked onto make it modernized, reduces the wastage of water resources as the water resources are quickly reducing, which poses a big threat to human life on the planet. Irrigation system is very crucial for the agriculture farm along with the monsoon raining system, which seasonal. It also provides large ample employment opportunities to the people. Unfortunately, many farmers still use the traditional methods of farming which results in low yielding of crops and fruits. But wherever automation had been implemented and human beings had been replaced by automatic machineries, the yield has been improved.
Most of the papers signifies the use of wireless sensor network which collects the data from different types of sensors and then send it to main server using wireless protocol. The collected data provides the information about different environmental factors which in turns helps to monitor the system. There are number of other factors that affect the productivity to great extent. These factors include attack of insects and pests which can be controlled by spraying the crop with proper insecticide and pesticides. There is also possibility of thefts when crop is at the stage of harvesting. Fig. 1 shows the IoT based agriculture management system.

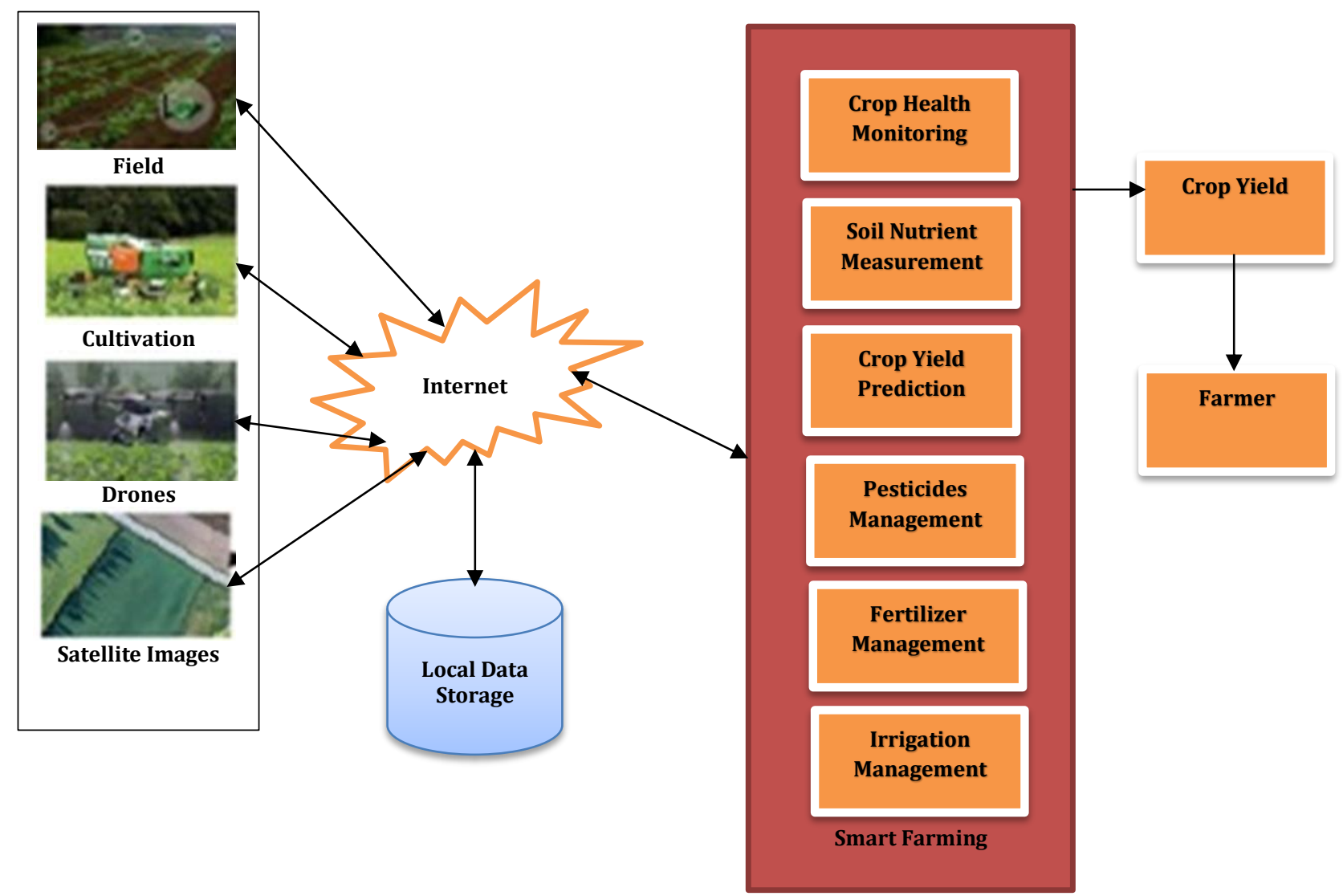

Fig. 1: IoT based agriculture management system (Rajasekaran and Anandamurugan, 2019)

Even after harvesting, farmers also face problems in storage of harvested crop. So, in order to provide solutions to all such problems, it is necessary to develop integrated system which will take care of all factors affecting the productivity in every stages like; cultivation, harvesting. So, in order to provide solutions to all such problems, it is necessary to develop integrated system which will take care of all factors affecting the productivity in every stages like; cultivation, harvesting and post harvesting storage. The 1800s brought the chemical fertilizers, grain elevators, and the tractor. The farmer starts using technological equipment for cultivating the various farm products in the late 1900s. At the end of the $20^{\text {th }}$ century, the farmer starts using modern machinery along with an automated system for farming purposes. Nowadays, IoT is the key to connect everything to the one central controller to continues to advance. It becomes more important in the disruptive innovation segment (BBVA, 2015; Ali, 2019). IoT gives boost across the different areas of industry, such as military, manufacturing, transportation, and agriculture. Fig. 2 shows sensory system deployment in the agriculture field.

In this Plant Watering System, the Soil Moisture Sensor checks the moisture level in the soil, and if the moisture level is low, then Arduino switches on a water pump to provide water to the plant. The watering system gets switched off on its own when the sensor system finds enough moisture in the soil. The proposed model consists of the soil moisture sensor, temperature, PIR sensor, and humidity sensor for the purpose of monitoring the crop. To check the moistures in the soil, the sensor-based system is installed on the farm, and if it detects the moisture level and finds it the below then defined, the system automatically turns on the watering system to the farm. The water pump gets 
automatically off when the system finds enough moisture in the soil.

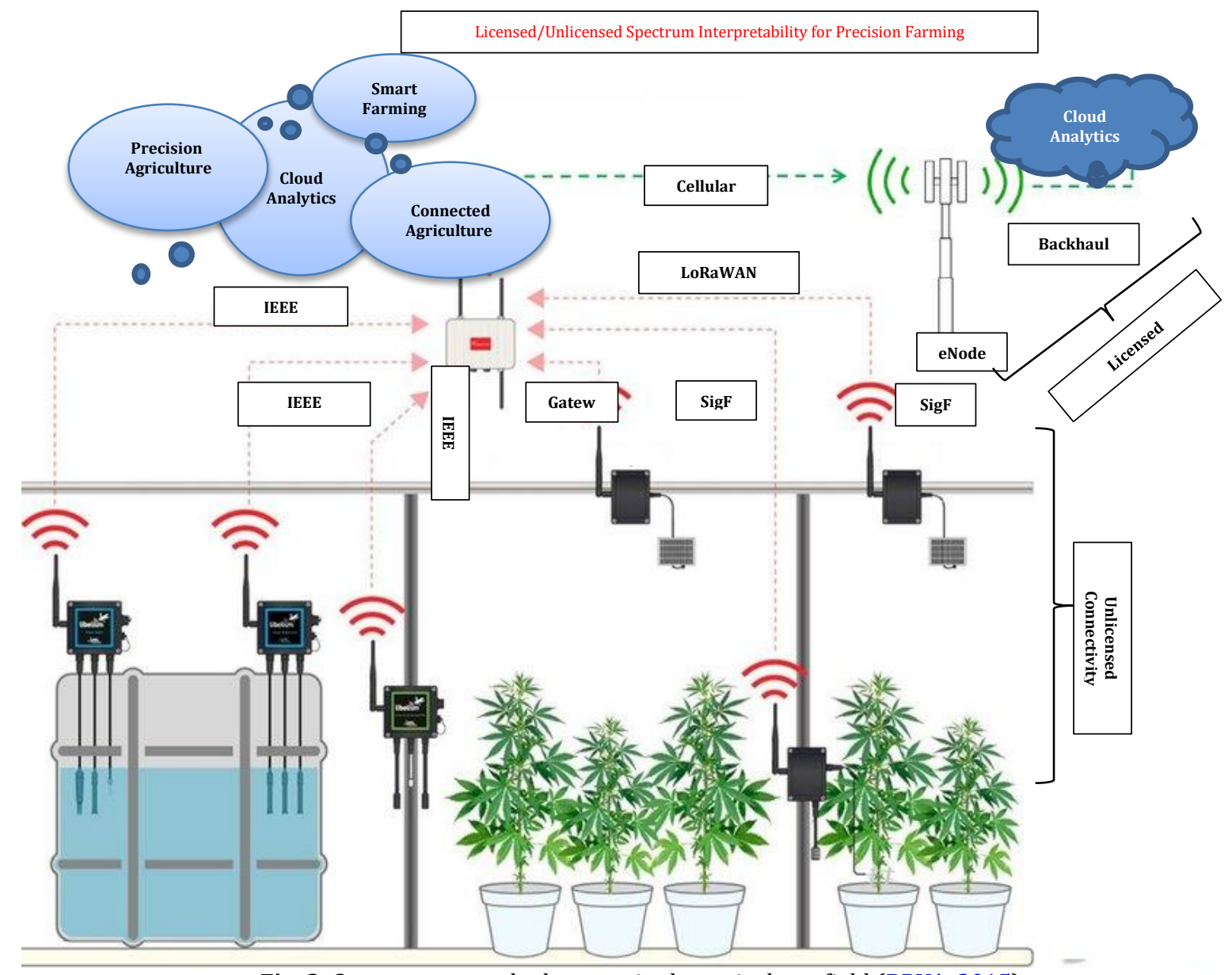

Fig. 2: Sensory system deployment in the agriculture field (BBVA, 2015)

\section{Literature review}

IoT is the very popular field now a day to embed with various types of services in the modern world. In several studies of world organization predicted based on the scientific studies that in the near future most of the wars will be because of water as the water bed is going down and rivers are becoming dry quickly. Due to the above mention reasons, it is the need, it is urgent to properly utilize the water resources to cope with future water shortage for human and agriculture proposes. To handle this problem, Nandurkar et al. (2014) presented the use of temperature and moisture sensors at suitable locations for the monitoring of crops in agriculture farms. The researcher presented an algorithm with threshold values of temperature, and soil moisture can be programmed into a microcontroller-based gateway to control water quantity. The proposed system can be powered by using the solar panels and can have full-duplex communication link based on the sensor network interface that allows data inspection and irrigation scheduling to be programmed through IoT by using web page (Gutiérrez et al., 2013; Ali et al., 2016). The enhancement in the technological area, especially in wireless sensor networks, made it possible to use in monitoring and control the activities in precision agriculture (Gutiérrez et al., 2013). Fig. 3 shows remote monitoring of the crop by using IoT.

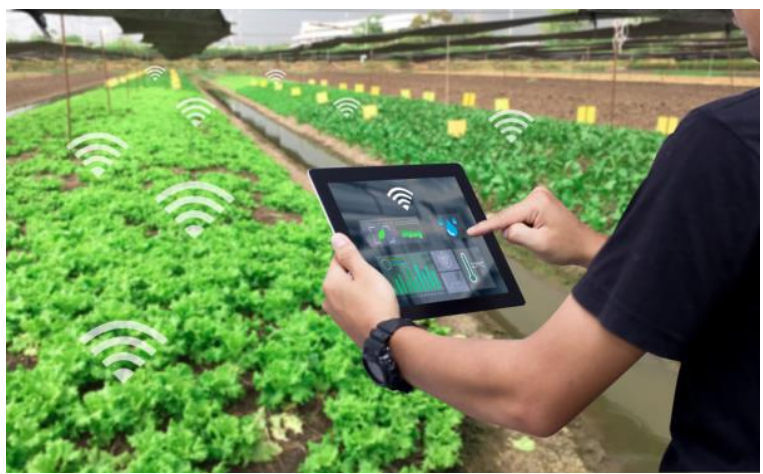

Fig. 3: Remote monitoring of the crop by using IoT

IoT example, any object which is capable of identifying, connecting, and communicating with other objects is an example of IoT (Rajasekaran and Anandamurugan, 2019). The population of the world is expected to grow by $70 \%$ by 2050 (FAO, 2009), to overcome the food shortage the world organizations must overcome increasing water shortages, limited availability of resources to provide the daily life needs. IoT can play a vital role in overcoming the food shortage in the future by pushing the farmer to use smart farming by using wireless sensor networks along with IoT. Even smart farming is becoming very common, but still, it needs to do a lot of the awareness in a remote area of countries where farmers are not qualified and well connected with the latest technologies. IoT applications in 
agriculture and IoT will help farmers meet the world's food demands in the coming years.

\section{Proposed system modules}

The proposed system simulated by using simulation tools, with the below modules, and implemented to test the model in real-time by using the different types of sensor nodes that are integrated with IoT. The first stage of this proposed system is based on simulation findings that are analyzed to be implemented in real, and results are very much acceptable. Fig. 4 shows a block diagram of the sensory system.

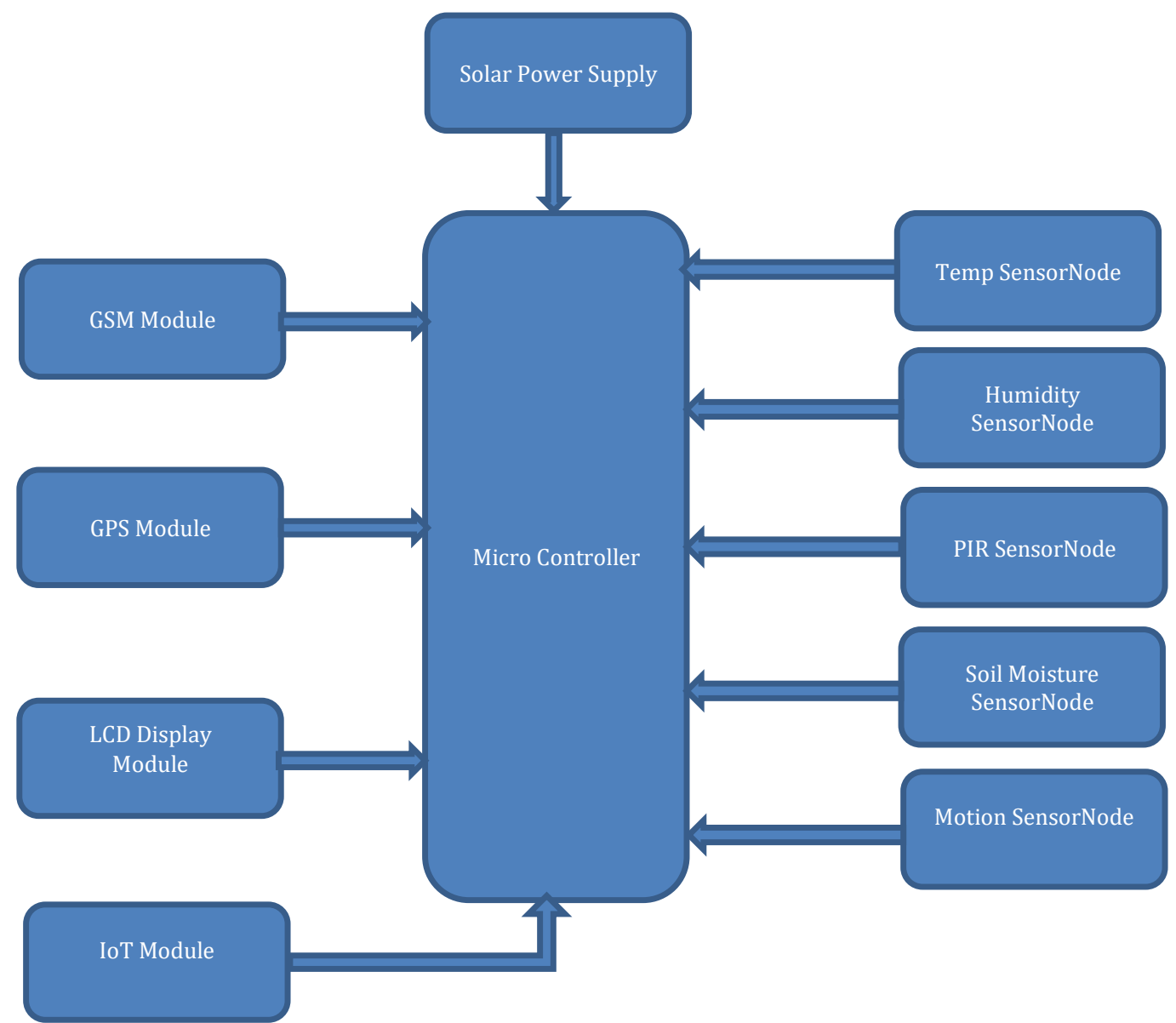

Fig. 4: Block diagram of sensory system

The proposed system includes the temperature, humidity, PIR, soil moisture, and motion sensor nodes for the IoT based monitoring agriculture crops. Fig. 4 shows the different modules of the sensory system in which temperature and soil sensors are connected with other modules of the system. Arduino controller will be used to connect various types of sensors and with processing units along with remote monitoring and managing system for the agriculture field. Fig. 5 shows the Arduino controller.

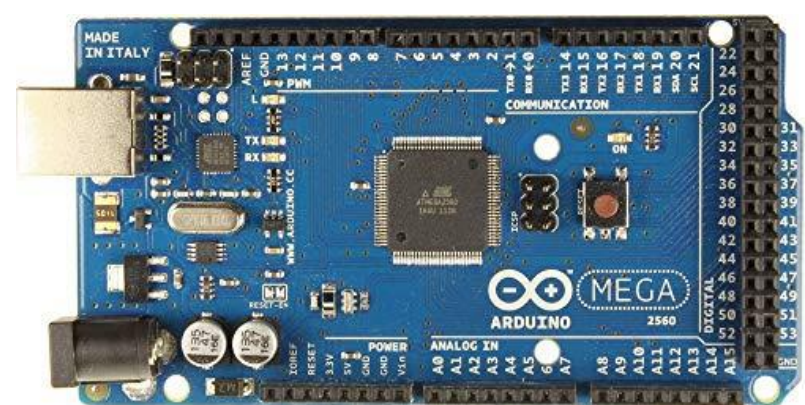

Fig. 5: Arduino controller

\subsection{Soil moisture sensor}

Soil consists of the blend of segments, which includes the minerals and other natural particles. Soil moisture sensor is a device that measures the moisture content of the soil. The sensor is capable of both analog and digital signal detection. Fig. 6 shows the soil moisture sensor and block diagram.

\subsection{Temperature sensor}

The temperature is the key element in the farming environment, and it has a lot of influence on the yield. The Celsius scaling of the temperature is linear to the voltage of the LM 35 sensor. It does not provide any external trimming. It has a wide operating range. The maximum output is $5 \mathrm{~V}$. It consumes a minimum amount of electricity. Thus, it is energy-efficient, effective, and is user friendly in use. Fig. 7 shows a temperature sensor. 


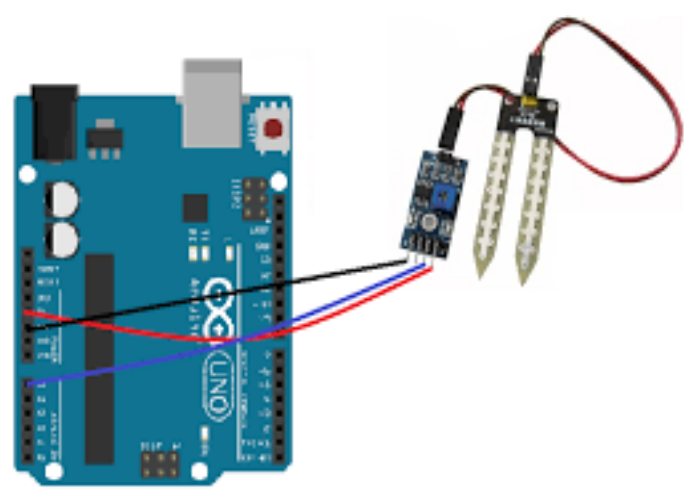

Fig. 6: Soil moisture sensor and block diagram

\subsection{Humidity sensor}

This module measures the water vapors in the environment, which is the key to the growth and health of the crop (Fig. 8). The water vapors are the predetermined volume of water in the air/environment, and it is the proportion of moisture in the environment. It is the measure of water vapor (water that has abandoned a fluid to an undetectable gas) noticeable all around.

In the proposed framework for the monitoring and managing of the agricultural farm, it includes various features such as remote monitoring, temperature, and moisture sensing system, intruder scaring, security, and leaf wetness along with the proper watering system. It is supposed that various sensor nodes are deployed at different locations on the farm to measure and monitor the crop and its environment. All the parameters are controlled and monitored using remote devices through the internet, and all the required operations are performed through microcontroller interfacing the installed sensor systems.

Fig. 9 shows the block diagram of the framework of the smart monitoring managing system of which includes the different layers of the system. The sensor nodes measure the temperature, humidity, moisture, and motion of any pest and the fetched information transferred through the gateway to the IoT platform for analysis and decision making. The processed data is stored using dedicated servers for future use and decision making. Fig. 9 shows a block diagram of the sensory system.

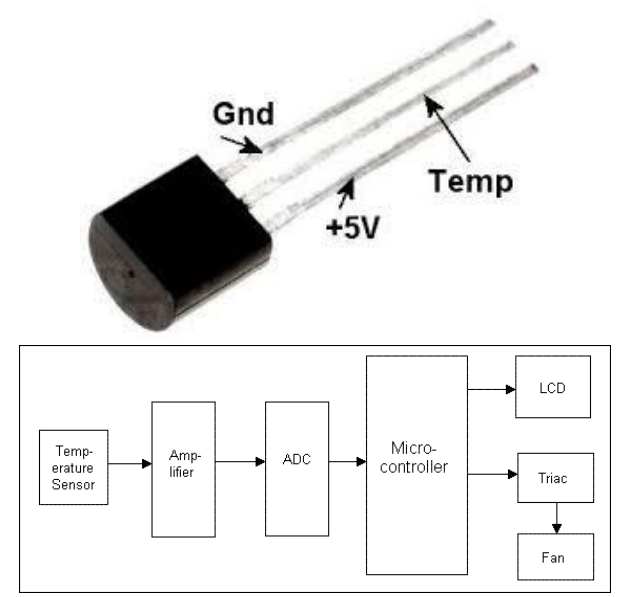

Fig. 7: Temperature sensor

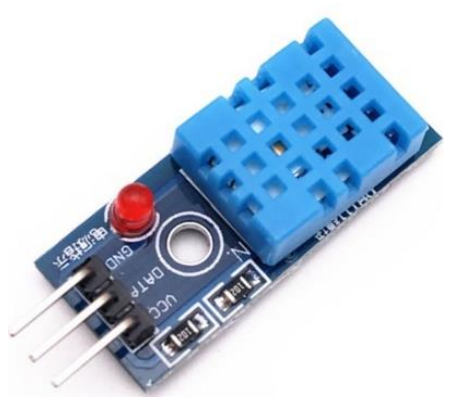

Fig. 8: Humidity sensor

\section{Proposed system}

Fig. 10 shows the algorithm for the framework of smart monitoring and managing the farm. Sensory modules measure the different vitals of the forming environment and fetched information sent for processing and analyzing to take action. Based on the analysis of the data, further actions are taken for the betterment of the crop to increase the yield.

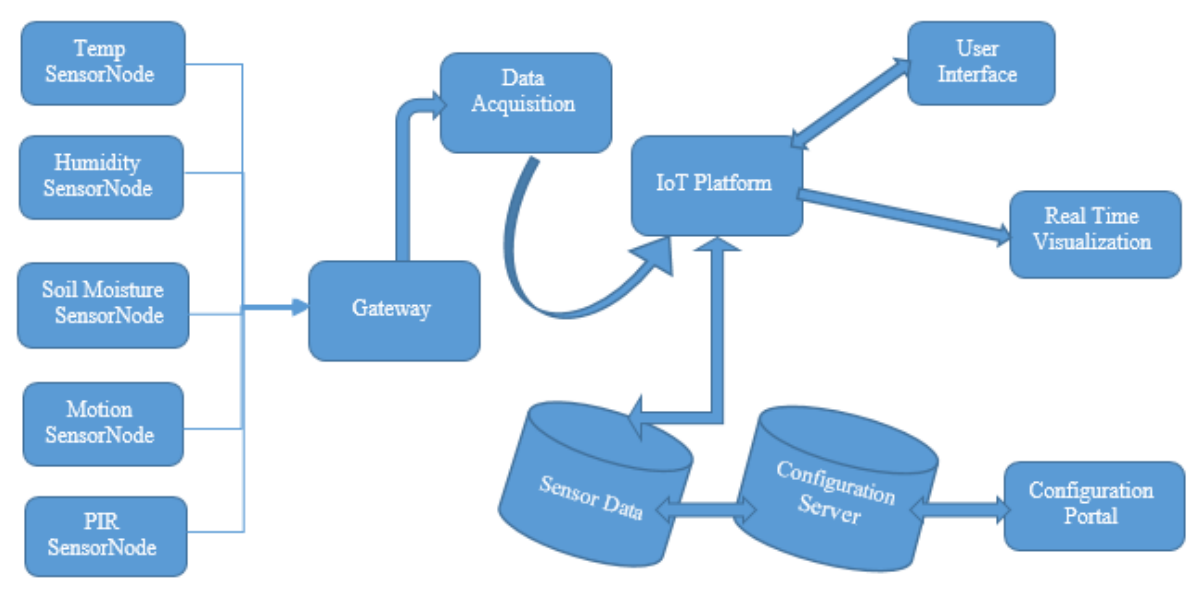

Fig. 9: Block diagram of the sensory system 


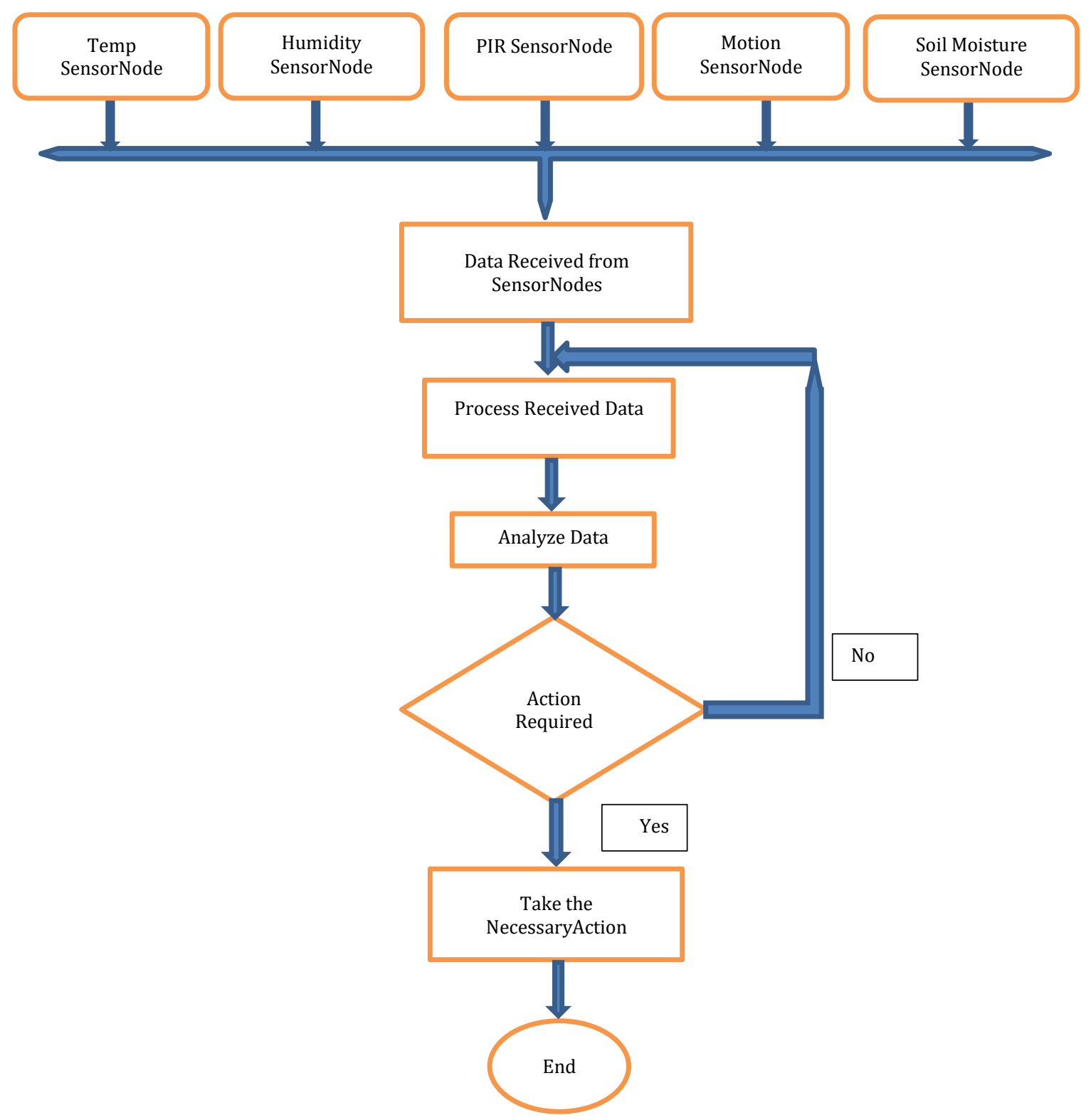

Fig. 10: Proposed Algorithm to monitor and manage smart farming

The graph in Fig. 11 shows the sensed temperature of the soil and air during the day with regular intervals. The measured data is stored and analyzed with different aspects like the sun goes up. The air temperature increases quickly as compared to soil temperature. Both readings reach its maximum around $4 \mathrm{pm}$ due to effect of the sunlight, and after this point, it starts decreasing, and air temperature falls below 30 degrees Celsius by 10 pm, and it continues dropping, and due to this reason, the soil temperature falls as well and goes around 16 degrees Celsius by that time. When the temperature goes higher than the defined threshold, the proposed system is capable of starting watering the farm where it is needed.

The graph in Fig. 12 shows the humidity level at different times of the day, and it shows that level is high in the morning and read around 90\%, and as the sun comes up, the humidity level also goes low.

As time goes in the day, by $4 \mathrm{pm}$, the humidity level falls up to $50 \%$, and it becomes directly proportional to the air temperature. If the air temperature increases, the humidity level falls as well. Based on the fetched data, the automated system takes the required action to keep the temperature and humidity level up to a level which don't affect the crop. By maintaining humidity and temperature level up to the required standard, and it varies with respect to the crop type. The proposed system automatically switches on the sprinkling system to maintain the humidity level as required, and varies with the type of crop.

\section{Conclusion}

In this research project, the real-time monitoring and managing of the agriculture farm are designed and tested by using the experimental field. By implementing the proposed system and deploying in the farm, it keeps monitoring and managing the farm to get the maximum crop yield. For the monitoring and managing, the sensor nodes need to be installed in the experimental field for collecting the data for monitoring purposes. Further, we need to connect 
the installed system in the agriculture farm by using IoT with the support of the Wi-Fi to send the sensed data to the data center for analysis.

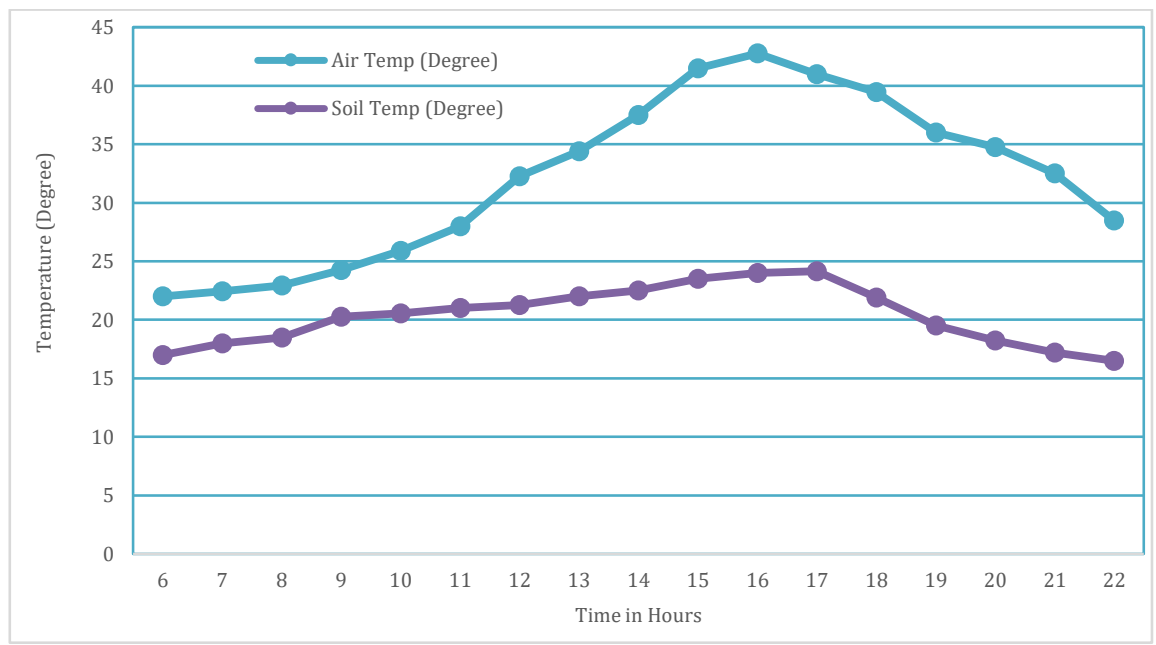

Fig. 11: Sensor data measured from air and soil by using sensory nodes

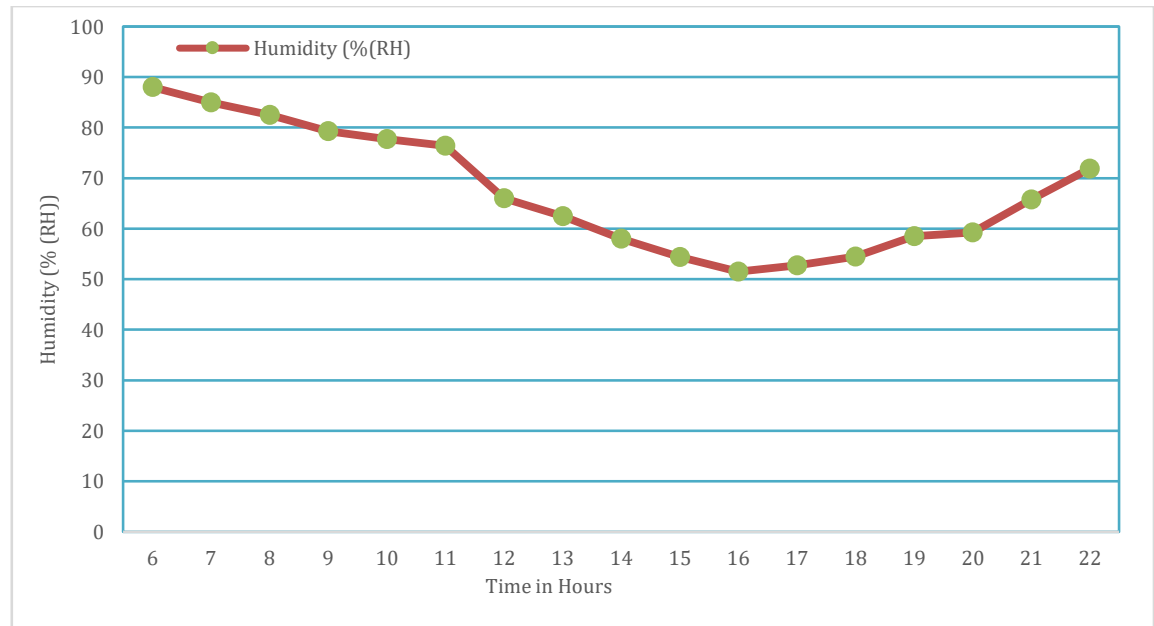

Fig 12: Sensor data measured from air by using sensory nodes

In the proposed system, the functions of different modules have been discussed. The air temperature, soil temperature, and humidity monitoring system with the support of IoT are tested for these parameters. The sensed data is sent to the cloud to store for future use and can be used by other users for the analysis.

\section{Acknowledgment}

This work is part of the research study titled "Internet of Things (IoT) embedded Smart Sensors System for Agriculture and Farm Management" supported by Deanship of Research, Islamic University of Madinah, Almadinah Almunwarah, Kingdom of Saudi Arabia.

\section{Compliance with ethical standards}

\section{Conflict of interest}

The authors declare that they have no conflict of interest.

\section{References}

Ali A, Ikpehai A, Adebisi B, and Mihaylova L (2016). Location prediction optimisation in WSNs using Kriging interpolation. IET Wireless Sensor Systems, 6(3): 74-81. https://doi.org/10.1049/iet-wss.2015.0079

Ali SA (2019). Health monitoring and management system by using wireless sensor network and internet of things (IoT). International Journal of Computer Science and Network Security, 19(12): 179-184.

BBVA (2015). The Internet of things, booming business models. Banco Bilbao Vizcaya Argentaria, Bilbao, Spain.

FAO (2009). 2050: A third more mouths to feed. Food and Agriculture Organization of the United Nations, Rome, Italy.

FAO (2017). Water for sustainable food and agriculture: A report produced for the G20 presidency of Germany. Food and Agriculture Organization of the United Nations, Rome, Italy.

Gutiérrez J, Villa-Medina JF, Nieto-Garibay A, and Porta-Gándara MÁ (2013). Automated irrigation system using a wireless sensor network and GPRS module. IEEE Transactions on Instrumentation and Measurement, 63(1): 166-176. https://doi.org/10.1109/TIM.2013.2276487

Nandurkar SR, Thool VR, and Thool RC (2014). Design and development of precision agriculture system using wireless sensor network. In the $1^{\text {st }}$ International Conference on 
Automation, Control, Energy and Systems, IEEE, Hooghy, India: 1-6.

https://doi.org/10.1109/ACES.2014.6808017

Rajasekaran T and Anandamurugan S (2019). Challenges and applications of wireless sensor networks in smart farming: A survey. In: Peter J, Alavi A, and Javadi B (Eds.), Advances in big data and cloud computing: 353-361. Volume 750, Springer, Singapore, Singapore.

https://doi.org/10.1007/978-981-13-1882-5_30

Suarez J, Quevedo J, Vidal I, Corujo D, Garcia-Reinoso J, and Aguiar RL (2016). A secure IoT management architecture based on information-centric networking. Journal of Network and Computer Applications, 63: 190-204.

https://doi.org/10.1016/j.jnca.2016.01.016

Yang A, Kim J, Cho B, and Park H (2018). An architecture and design of data converter for IoT-based smart farm. International Journal of Smart Home. 12(4): 7-12. https://doi.org/10.21742/ijsh.2018.12.4.02

Zhang Y and Shen Y (2019). Wastewater irrigation: Past, present, and future. Wiley Interdisciplinary Reviews: Water, 6(3): e1234.

https://doi.org/10.1002/wat2.1234 